\title{
Verification of Precipitation Forecasts from the UK Operational Limited-area Model
}

\author{
By C.D. Hall \\ Meteorological Office, Bracknell, Birkshire, UK \\ (Manuscript received 29 October 1986, in revised form 26 January 1987)
}

\begin{abstract}
Precipitation forecasts from the UK operational limited-area model have been verified and some results are presented here. Total forecast precipitation over 6-month summer and winter seasons is compared with high-resolution data obtained from the UK raingauge network. In general good agreement is found between the model and observations though some systematic errors are evident. In particular precipitation over high ground in the west and north of the UK is underforecast. Forecasts of 6-hour accumulations are assessed by comparing with observations from 369 stations over the European area covered by the model. Threat scores are given for threshold values of 0.05 and $2.0 \mathrm{~mm}$ and for various forecast periods. It is found that frontal rain is usually well forecast. A separate assessment was made of the representation of fronts in the model; 72 percent of 24-hour forecasts of frontal position over the UK are found to be within $100 \mathrm{~km}$ of the verifying position.
\end{abstract}

\section{Introduction}

High-resolution limited-area models have been used operationally in the UK since 1972 and have made an important contribution to the quality of forecasts issued nationally. They include a full parametrization of the moist diabatic processes in the atmosphere and grid-point precipitation is one of the forecast parameters. The accuracy of precipitation forecasts from limited-area models has been described by many authors (e.g. Horodeck and Hirano, 1979; Charba and Klein, 1980) but in the UK, although subjective forecasts have been verified for many years, no verification of forecasts from numerical models has been attempted until quite recently. Verification statistics obtained during 1985 and 1986 are presented here for much of the European area covered by the model and in more detail for the UK area.

\section{The limitcd-area model}

The present model which has been oper- ational since 1982 has a finite-difference formulation on a latitude-longitude grid covering the area $30 \mathrm{~N}$ to $80 \mathrm{~N}$ and $40 \mathrm{E}$ to $80 \mathrm{~W}$. The gridlength is about $75 \mathrm{~km}$ at $50 \mathrm{~N}$ and there are 15 levels in the vertical on a sigmacoordinate system. The data assimilation cycle is 3-hourly using all data available within $1 \frac{1}{2}$ hours of the synoptic hours $00 Z$, 03Z, 06Z, 09Z, 12Z, 15Z, 18Z and 21Z. An analysis system based on the method of repeated insertion is used with divergence damping and horizontal diffusion to reduce grid-scale noise. Boundary conditions are provided by a global model having the same vertical resolution but only half the horizontal resolution. The forecasting system is described in more detail in Bell and Dickinson (1987) and Bell (1986).

Precipitation in the model derives from supersaturation as a result of dynamical processes and from a parametrization scheme for deep convection. The convection scheme is based on parcel theory; an ensemble of parcels given an initial bouyancy are allowed 
to rise through the model layers until they reach equilibrium. They can be modified by entrainment and detrainment as well as the moist diabatic processes producing precipitation. The scheme is also described in Bell and Dickinson (1987).

\section{The verification method}

The model is run twice a day from $00 Z$ and $12 Z$ analyses to produce forecasts up to 36 hours ahead and both runs are used for verification purposes. Forecasts of grid-point 6 -hourly precipitation amounts for the periods $0-6,6-12,12-18,18-24,24-30$ and $30-36$ hours are verified against observations from a network of stations (Fig. 1) over much of the European area covered by the model. Some results (not presented here) were produced verifying model grid-point forecasts against the average of all the observations available within a grid box surrounding the point. However, there were complications in interpreting the results as the frequency of occurrence of precipitation varied considerably with the number of observations used in the averaging. The station network used here has been chosen to be as uniform as possible; where there are several stations reporting 6-

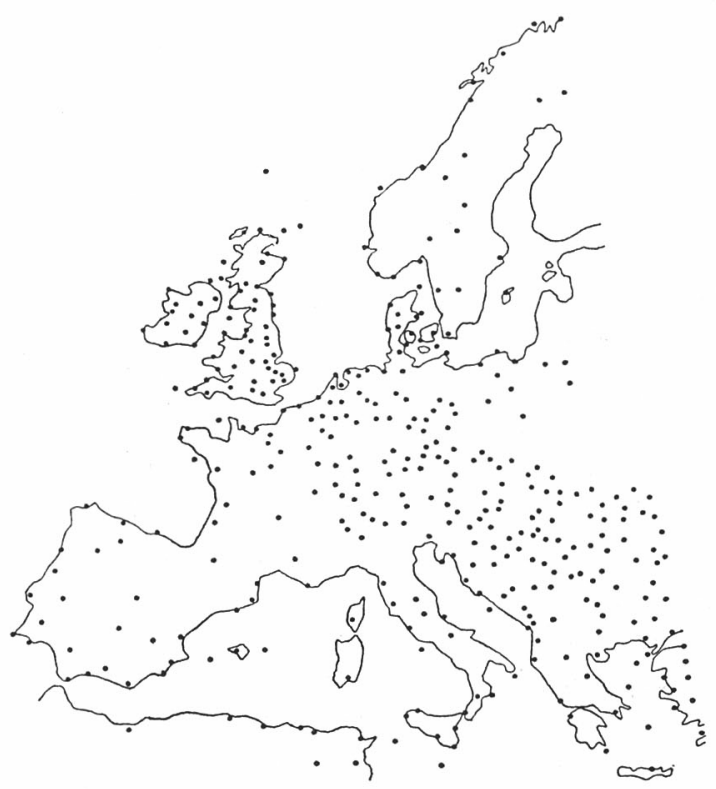

Fig. 1. The location of observing stations used for precipitation verification. hourly precipitation amounts within the grid box surrounding a model grid point, only one has been taken. Each observation is compared with the forecast at the grid point nearest the station position and the verification statistics presented here are derived from means over all the relevant stations in the network.

Few quality control checks can be performed on precipitation data at this resolution. Only one check is made here: consistency is ensured between a report of measurable precipitation and a report of precipitation in the previous 6 hours in the past-weather group of the SYNOP observation.

A threat score $T_{p}$ is used as a measure of the accuracy of forecasts of the event of precipitation greater than or equal to the amount $p$ at a given location.

$$
T_{p}=C /(F+O-C)
$$

where $C$ is the number of correct forecasts, $F$ is the number of forecasts of the event to occur and $O$ is the number of observations of the event.

Strictly, model forecast precipitation amounts which are representative of the amount over the area of a grid box, are not directly comparable with observations at a fixed location, and this difference should be taken into account when interpreting the figures. Over the UK use has been made of a much denser coverage of stations to give estimates of observed areal 24-hour amounts (Thompson, Barrie and Ayles, 1981), which can in particular resolve the effects of orography on the grid scale of the limited-area model. This data (MORECS) is more suitable for comparison with forecasts from numerical models but it is not available for 6 or 12hour periods. It has only been used to investigate the systematic errors in the model precipitation amounts.

\section{Verification results}

a. Verification of seasonal precipitation amounts over the UK

Figures 2 and 3 show the forecast $0-24$ hour precipitation amounts over the UK area 
(1) MODEL T+24 FORECASTS

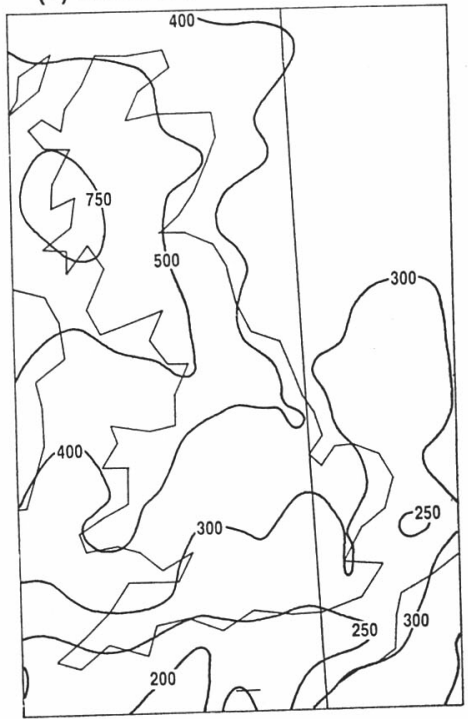

(2) OBSERVED

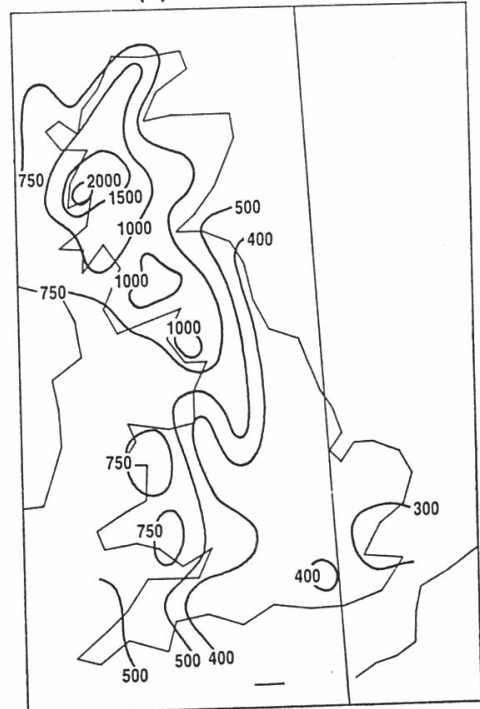

Fig. 2. Total precipitation in $\mathrm{mm}$ for the period April-September 1985;

(1) 0-24 hour forecast accumulations, (2) observed accumulations.

(1) MODEL T+24 FORECASTS

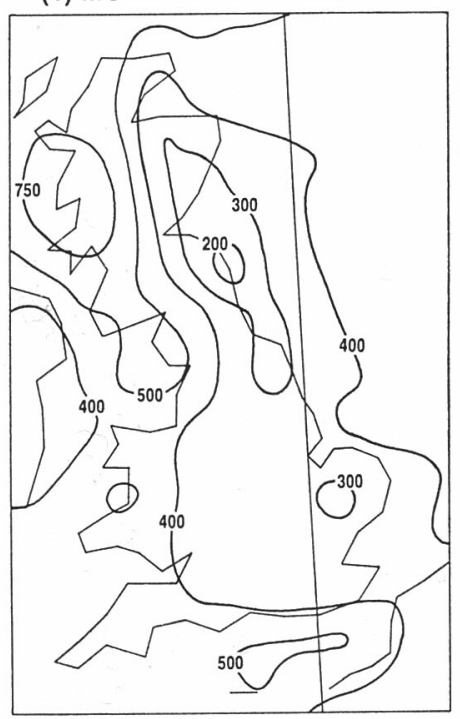

(2) OBSERVED

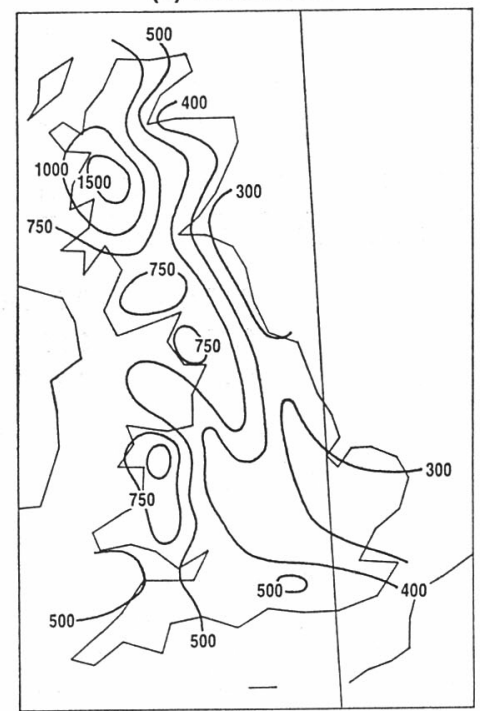

Fig. 3. Total precipitation in $\mathrm{mm}$ for the period October 1985-March 1986 ;

(1) 0-24 hour forecast accumulations, (2) observed accumulations.

summed over all model runs starting from $00 \mathrm{Z}$ analyses during the last warm (April to September 1985) and cool (October 1985 to March 1986) seasons. Values for model runs starting from $12 Z$ analyses (not shown) are almost identical. These figures represent the seasonal precipitation amount over the UK forecast by the model in the first 24 hours of integration. The corresponding observational MORECS data are shown alongside.

The main deficiency of the model forecasts in both seasons is a failure to show enough east-west contrast in the precipitation amounts, mainly due it appears to an underestimation 
of precipitation over the high ground in the North and West. The observed maximum over Northwest Scotland is present in the forecasts but is too small while over the high ground of Wales it is almost absent. Over the south eastern half of the UK where the surface elevation is generally low, forecast amounts are close to or a little less than observed values. The orographic heights used by the model are grid-box mean values and on a scale of $75 \mathrm{~km}$ many features causing actual enhancement of precipitation will not be resolved.

\section{b. Verification of forecasts of 6-hour precipitation amounts}

The frequency of occurrence of four categories of forecast and observed precipit- ation at the 52 verifying UK stations during the period January to April 1986 are shown in Fig. 4 and at the 369 verifying stations in the larger European area in Fig. 5. Values for 18-24 forecast amounts are given, and the precipitation categories are $P<0.05$ $\mathrm{mm}$ (Nil) ; $0.05 \mathrm{~mm} \leqq P<2.0 \mathrm{~mm}$ (light); 2.0 $\mathrm{mm} \leqq P<10.0 \mathrm{~mm}$ (moderate); and $10.0 \mathrm{~mm} \leqq$ $P$ (heavy). A report of trace rainfall has been regarded as nil. Threat scores for the threshold amounts $0.05 \mathrm{~mm}$ and $2.0 \mathrm{~mm}$ are also presented for each of the six forecast periods from $0-6$ hours to $30-36$ hours.

It is clear that occurrences of light precipitation are far more common in the model forecasts than observed at the verifying stations. In part this may reflect systematic errors in the parametrization of preci-
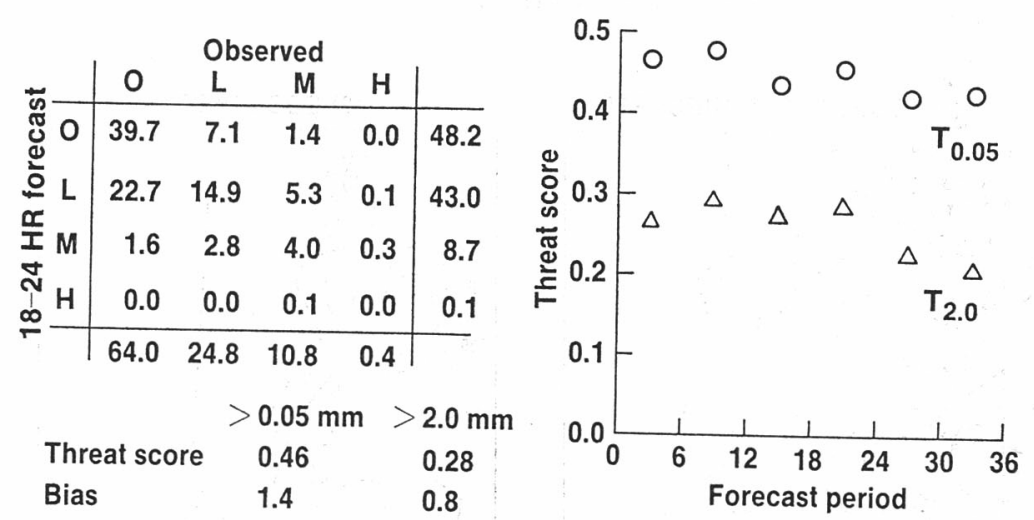

Fig. 4. Verification of precipitation forecasts in the UK area for the period January-April 1986.
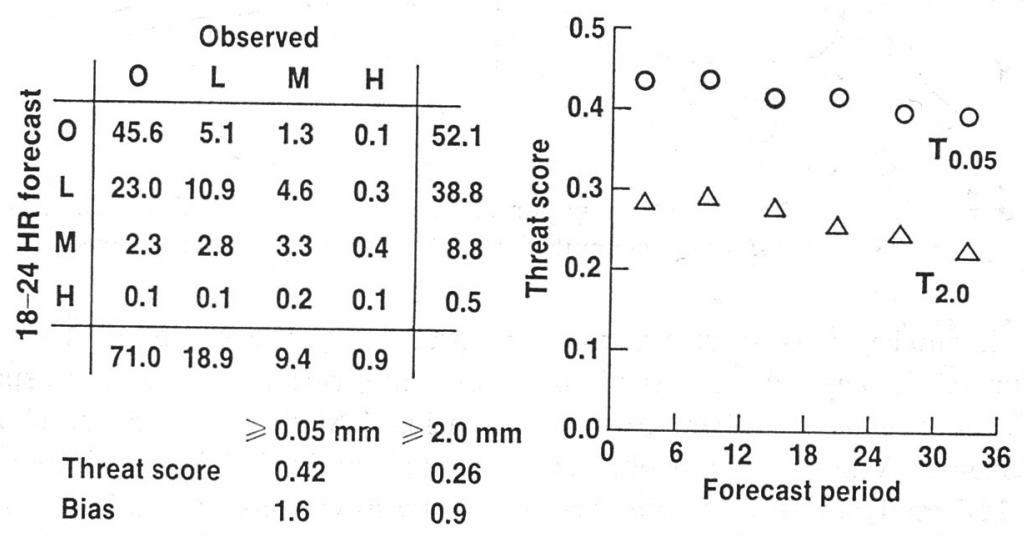

Fig. 5. Verification of precipitation forecasts in the European area for the period January-April 1986. 
pitation in the model, but some difference like this may be expected between forecasts which represent mean values over a grid box and observations at a fixed location.

\section{c. Verification of forecast frontal position}

Frontal systems associated with lows moving across the Atlantic are the most important source of precipitation over the UK. Frontal structure is usually realistically represented by the model fields and on the large majority of occasions it is found possible to define frontal position precisely and unambiguously by using the low-level temperature and moisture fields. An example of a $T+24$ forecast of $850 \mathrm{hPa}$ wet-bulb potential temperature is shown in Fig. 6 along with the verifying analysis. The frontal zone is no more than 2 grid lengths wide over much of the region, the model's frontal boundary being taken to be on the warm side of the sharp gradient in the field. In this case there is an error in the frontal position of about $130 \mathrm{~km}$ over the UK. During a two-year period between November 1983 and October 1985 subjective assessments were made of the difference between the forecast position of fronts using model $T+24$ fields and the verifying position from an analysis of observational data. This estimate of model error was made at $00 Z$ and $12 Z$ each day only for those fronts lying over the UK where the data coverage is good. The results are shown in Table 1. The errors $\mathrm{E}$ have been classified by frontal type and speed of movement of the front. A positive error indicates that the forecast front has passed the verifying position; ie there was a positive model phase error. The values give the percent frequency for different types of front ; slow (s) refers to those fronts with speeds less than $10 \mathrm{~ms}^{-1}$ and fast (f) to those with speeds greater than that.

72 percent of all $T+24$ forecasts of frontal position are within $100 \mathrm{~km}$ of the analysed position. There does not seem to be much variation in the magnitude of the model errors with frontal type or speed of movement, but clearly there is a slight bias in the

Table 1. Subjective estimates of errors (E) of $\mathrm{T}+24$ forecasts of frontal position. Values are percent frequency for different types of front; slow (s) refers to those fronts with speeds less than $10 \mathrm{~ms}^{-1}$ and fast (f) to those with speeds greater than $10 \mathrm{~ms}^{-1}$.

\begin{tabular}{|c|c|c|c|c|c|c|c|}
\hline & \multicolumn{2}{|c|}{ Cold } & \multicolumn{2}{|c|}{ Warm } & \multicolumn{2}{|c|}{ Occlusion } & \multirow{2}{*}{ All } \\
\hline & $\mathrm{S}$ & $\mathrm{F}$ & $\mathrm{S}$ & $\mathrm{F}$ & $\mathrm{S}$ & $\mathrm{F}$ & \\
\hline $\mathrm{E}<-100 \mathrm{~km}$ & 9 & 10 & 9 & 10 & 10 & 5 & 9 \\
\hline $\begin{aligned}- & 100 \mathrm{~km}<\mathrm{E}< \\
& 100 \mathrm{~km}\end{aligned}$ & 72 & 67 & 74 & 70 & 77 & 67 & 72 \\
\hline $\mathrm{E}>100 \mathrm{~km}$ & 19 & 23 & 18 & 20 & 13 & 28 & 19 \\
\hline No of cases & 235 & 88 & 117 & 69 & 103 & 46 & 658 \\
\hline
\end{tabular}
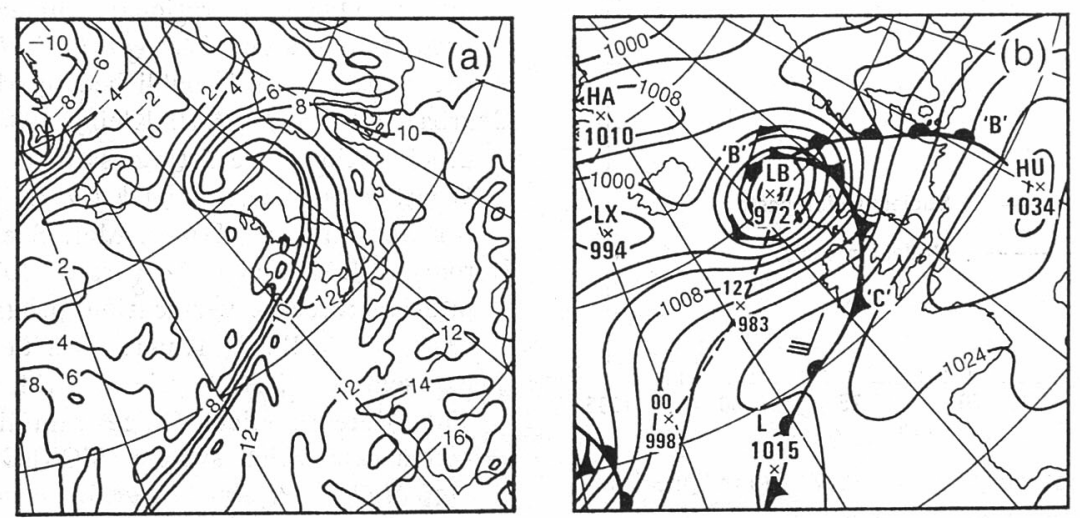

Fig. 6. (a) An example of a $\mathrm{T}+24$ forecast of $850 \mathrm{hPa}$ wet-bulb potential temperature used to define the forecast frontal position, and (b) the verifying analysis, data time $00 \mathrm{Z} 11 / 10 / 85$. 
forecasts towards positive phase errors, the cause of which is not understood. That the accuracy of the forecasts is approaching the resolution of the model points to large-scale atmospheric motion as the factor determining the accurate representation of frontal processes in the model.

\section{d. Long-term trends in the accuracy of precipitation forecasts}

The accuracy of subjective forecasts of precipitation issued by the Central Forecasting Office at Bracknell has been monitored for a long time and annual values over the period 1962-1985 are shown in Fig. 7. The occurrence of measurable precipitation at a point site (London) during the daytime period $06 \mathrm{Z}$ to $18 \mathrm{Z}$ is forecast on the previous day using data available at $12 Z$. This amounts to a 18-30 hour forecast and the percent correct are shown in the figure. There is a slight but distinct upward trend over the period especially after 1982 which marked the introduction of the latest high-resolution limitedarea model for forecasting use. The model has somewhat higher resolution than the old version and improved analysis and parametri-

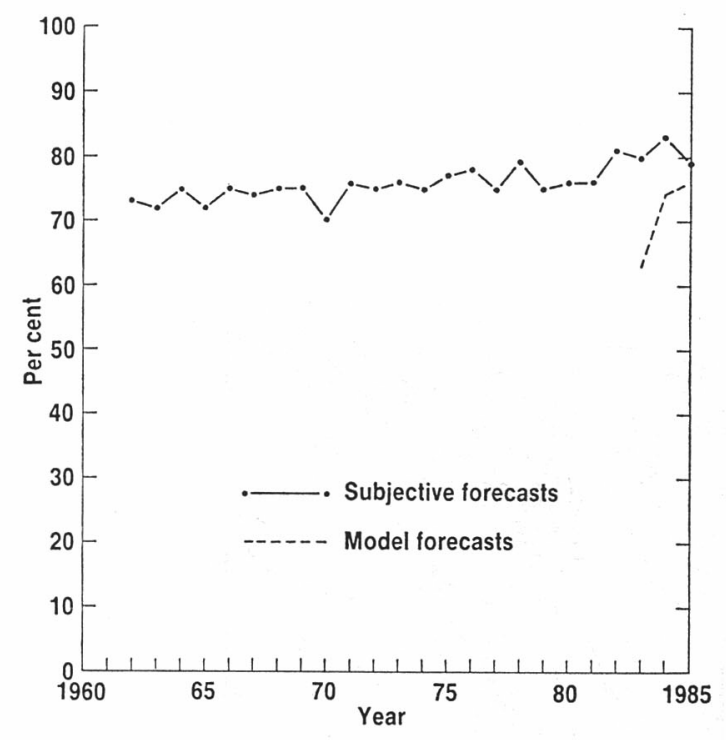

Fig. 7. Percent correct of 18-30 hour precipitation forecasts for London. zation schemes. The equivalent scores for the model shown by the dashed line are significantly lower than recent subjective scores but are now higher than the scores obtained in the sixties when no numerical forecasting guidance was available. It seems likely that numerical models have been a major factor in this upward trend in the accuracy of precipitation forecasts though the human forecaster can still make a significant contribution.

\section{Conclusions}

Current limited-area models with gridscale resolution of around $100 \mathrm{~km}$ or less are able accurately to represent the cycle of developing lows and their associated frontal systems which dominate the flow in middle latitudes. Figures presented here of the errors in forecasts of frontal position over the UK demonstrate this accuracy. Three biases in the UK operational limited-area model have been highlighted:

a) the underestimation of precipitation over high ground;

b) an excessive occurrence of forecast light grid-point precipitation; and

c) a slight positive phase error in the forecasts of frontal movement.

\section{References}

Bell, R.S., 1986: The Meteorological Office finemesh data assimilation scheme. Met. Mag. 115, p 161.

- and A. Dickinson, 1987: The Meteorological Office operational numerical weather prediction system. Meteorological Office Scientific Paper No. 41, published by HMSO.

Charba, J.P. and W.H. Klein, 1980: Trends in precipitation forecasting skill in the National Weather Service. Eighth Conf. Wea. Forecasting and analysis, Amer. Met. Soc. p 391.

Horodeck, J.M. and R. Y. Hirano, 1979: A precipitation forecast verification program. Fourth Conf. on N.W.P., Amer. Met. Soc. p 138.

Thompson, N., I. A. Barrie and M. Ayles, 1981: The Meteorological Office rainfall and evaporation calculation system (MORECS). Meteorological Office Hydrological Memorandum No 45. 